\title{
9
}

\section{THE PLURALITY OF EXPLANATORY GAMES}

\author{
C. Mantzavinos \\ University of Athens
}

\section{INTRODUCTION}

Whee models are currently dominating the discussions in the theory of scientific explanation. First, the causal/mechanistic

model which claims that an explanation consists in the identification of mechanisms understood as entities and activities organized such that they are productive of regular changes, from start to termination conditions (Salmon, 1984, Machamer et al. 2000). This is now the dominant approach in the social sciences (Hedström and Swedberg 1996, Elster 2007, Demeuleneare 2011). Mohamed Cherkaoui has been one of its protagonists, his position having been best articulated in his Invisible Codes (2005). Second, the unification approach, which claims that explanations are deductive arguments that provide understanding by fitting particular facts and events within a general theoretical framework (Friedman, 1974, Kitcher, 1981 and 1989, Bartelborth 2002). Finally, the manipulationist approach, which claims that explanatory activity consists mainly in answering the "what-if-things-had-been-different-question", i.e. it views an explanation primarily as enabling us to see what sort of difference it would have made for the explanandum if 
the factors cited in the explanans had been different in various possible ways (Woodward 2003).

I have shown elsewhere (Mantzavinos, 2013a) that these three approaches need not exclude one other, but they are compatible with each other, in the sense that each approach applies to different domains of science. Showing this kind of compatibility paves the way for the defense of the position of explanatory pluralism. This is a pluralistic account that allows for different ideal types of explanation, i.e. different exemplary accounts of classification of explanatory activities.

One fruitful way to illuminate explanatory pluralism is to acknowledge that at every moment of time there is a stock of explanations available in a society, proposed by ordinary people "in the wild" or by specialists organized formally or semi-formally within specific organizational structures such as churches, universities, etc. This explanatory reservoir is distributed among diverse individuals and groups in society under conditions of a cognitive division of labour. The terms of provision, control, and dissemination of explanations in this collective explanatory enterprise are regulated by the different rules that the participants have come to adopt over time. These rules incorporate the normative standards that guide the processes of the discovery and justification of explanations as well as the modes of their communication, dissemination, and adoption. They constitute the rules of the explanatory game that the participants are playing.

My aim in this paper is not to elaborate on the notion of an explanatory game, since I have done this elsewhere (Mantzavinos, 2013b). My aim is rather to argue for the plurality of explanatory games. At every moment of time there is a plurality of explanatory games in a society that take place in parallel. In other words, it is not only within science that different explanatory games are played, but also within society at large. Lay people use rules of representation, rules of inference and rules of scope in order to provide explanations about phenomena that interest them. Children permanently ask why-questions to their parents and receive responses that are aimed to satisfy their curiosity. The vast majority of explanations offered in a society are common-sense explanations by lay people, following quite rudimentary rules in their explanatory activities. However, these explanations very often, though by no 
means always, tend to change, and under appropriate circumstances they become more and more convincing. In other words, the explanatory labor is not only distributed among the different participants in the diverse games at a moment of time; they also evolve over time. This evolution takes place as the sets of rules that guide the activities of the explainers change over time. Thus, the broad picture is one of both a horizontal division of explanatory labor at a moment of time and a vertical division of explanatory labor over time. The horizontal division can be best conceptualized as a plurality of explanatory games existing in parallel at a time, and the vertical division as the rule-change of these games over time. I will elaborate further on this in what follows.

\section{THE HORIZONTAL DIMENSION}

At every moment of time there is a continuum of explanatory knowledge available in a society. This knowledge is produced while diverse communities (broadly defined to include any group of people) proceed in explanatory activities. Thus, many explanatory games take place concurrently. This is trivial, if one considers that one set of the constitutive rules of any explanatory game determines what counts as an explanandum. Human beings wish to explain a huge number of phenomena in their environment, so it is only natural to postulate that there, accordingly, must be a huge number of games. What makes the claim of plurality more interesting, however, is that the constitutive rules are also comprised by rules determining what must be taken as given and by rules determining the metaphysical presuppositions of the game. So, we can have explanatory games which have the same explananda, but differ in the rules determining what must be taken as given and/or what the metaphysical presuppositions are. Here the plurality becomes more interesting, because we can identify different explanatory games that deal with the same explananda, but which differ from one another on the basis of in what they assume as given and of their metaphysical assumptions.

Three important types here are mythical, religious and scientific explanatory games. There are cases in which these three types of explanatory games simply deal with distinct and different explananda and, 
thus, there is no overlap among them (consider the question of why angels need to have wings in order to fly). In many cases, however, these three types of games deal with the same explananda, but differ radically in what they take as given and in their metaphysical presuppositions. Consider the case of the emergence of the universe, cosmogony.

A prominent explanation that was produced in the framework of the Greek mythical explanatory game is best summarized in the following quotation from Hesiod's Theogony (114-138). ${ }^{1}$

Tell me these things, Olympian Muses, tell From the beginning, which first came to be? Chaos was first of all, but next appeared Broad-bosomed Earth, sure standing-place for all The gods who live on snowy Olympus' peak And misty Tartarus, in a recess Of broad-pathed earth, and Love, most beautiful Of all the deathless gods. He makes men weak, He overpowers the clever mind, and tames The spirit in the breasts of men and gods. From Chaos came black Night and Erebos. And Night in turn gave birth to Day and Space Whom she conceived in love to Erebos. And Earth bore starry Heaven, first, to be An equal to herself, to cover her All over, and to be a resting-place, Always secure, for all the blessed gods. Then she brought forth long hills, the lovely homes Of goddesses, the Nymphs who live among The mountain clefts. Then, without pleasant love, She bore the barren sea with its swollen waves, Pontus. And then she lay with Heaven, and bore Deep-whirling Oceanus and Koios; then Kreius, Iapetos, Hyperion, Theia, Rhea, Themis, Mnemosyne, Lovely Tethys, and Phoebe, golden-crowned.

Last, after these, most terrible of sons, 
The crooked-scheming Kronos came to birth

Who was his vigorous father's enemy.

A prominent explanation of cosmogony that was produced in the framework of the Christian explanatory game is mainly contained in the Book of Genesis, the first chapter of which I would like to quote at length:

In the beginning when God created the heavens and the earth, the earth was a formless void and darkness covered the face of the deep, while a wind from God swept over the face of the waters. Then God said, "Let there be light"; and there was light. And God saw that the light was good; and God separated the light from the darkness. God called the light Day, and the darkness he called Night. And there was evening and there was morning, the first day. And God said, "Let there be a dome in the midst of the waters, and let it separate the waters from the waters." So God made the dome and separated the waters that were under the dome from the waters that were above the dome. And it was so. God called the dome Sky. And there was evening and there was morning, the second day. And God said, "Let the waters under the sky be gathered together into one place, and let the dry land appear." And it was so. God called the dry land Earth, and the waters that were gathered together he called Seas. And God saw that it was good. Then God said, "Let the earth put forth vegetation: plants yielding seed, and fruit trees of every kind on earth that bear fruit with the seed in it." And it was so. The earth brought forth vegetation: plants yielding seed of every kind, and trees of every kind bearing fruit with the seed in it. And God saw that it was good. And there was evening and there was morning, the third day. And God said, "Let there be lights in the dome of the sky to separate the day from the night; and let them be for signs and for seasons and for days and years, and let them be lights in the dome of the sky to give light upon the earth." And it was so. God made the two great lights-the greater light to rule the day and the lesser 
light to rule the night-and the stars. God set them in the dome of the sky to give light upon the earth, to rule over the day and over the night, and to separate the light from the darkness. And God saw that it was good. And there was evening and there was morning, the fourth day.

Contemporary cosmology, the branch of physics that deals with the question of the emergence of the universe, proposes a big bang explanation. According to the general theory of relativity gravity is not a force, but the curvature of space time. The range of gravity is infinite since it is a property of space time itself and the evolution of the universe is ultimately dictated by gravity. A set of differential equations relates the dynamic quantities in the universe and turn them back in time. Simulations on computers relate initial conditions of the universe to different outcomes aiming at representations of the kind of universe we live in. Earlier astronomers, most prominently Edwin Hubble, observed that neighbouring galaxies of the Milky Way galaxy are receding away-the more distant they are, the faster were they found to be moving away. In other words, recessional velocity of a galaxy increases with its distance from the earth. Reversing this expansion scenario back in time, the inference is drawn that if galaxies are moving rapidly apart now, they must have been denser-with more matter and energy per unit volume-in the past. Going back in time, the whole universe should converge to a point of infinite density and extremely high temperatures, and this should be the starting point of big bang. The universe itself should have been an infinitely dense point which expanded to its present size. The age of the universe according to this Big Bang explanation is estimated to be 13,73 billion years.

Given that Hesiod was active between 750 and 650 BC and that his mythical explanation has been reproduced for centuries afterwards and that Genesis was composed in the late 7 th or the 6th century BC (according to the prevailing consensus of biblical scholars) the first two explanatory games have been unfolding in parallel for a long period of time. Today, nobody believes the mythical explanation of Hesiod to be true. Today, it is the religious explanatory game of the Genesis, along 
with the scientific explanatory game of cosmology, that are unfolding in parallel. (And there are other religious explanatory games that deal with the same explanandum, which I leave unmentioned here).

The biblical and the scientific explanatory game are structured around the same explanandum, but differ radically in the rules determining what must be taken as given and the rules determining their metaphysical presuppositions. In their everyday work, though the players of the respective games engage in their explanatory activities following the constitutive rules of their own game, they occasionally engage critically with the constitutive rules of the other games. This engagement is usually manifest in the rejection of what is taken as given by the players of the other game and a rejection of the metaphysical presuppositions that they employ. The ongoing debate on creationism is such an example.

\section{THE VERTICAL DIMENSION}

Explanatory games evolve over time. An important factor of their evolution is that even the most fundamental of the constitutive rules, the ones that determine what counts as an explanandum, evolve over time. The legitimate why-questions to ask in a specific domain change over time, something that should not be astonishing. ${ }^{2}$

The change in the constitutive rules is certainly important, but the prevalent change of all other kinds of rules is of equal importance, making the playing of an explanatory game an inherently dynamic enterprise. The means of representing phenomena evolve over time-in contemporary science, artefacts like graphs, computer monitor displays, etc. are constantly developed further as are abstract means of representation like mathematical models. The same is the case with the rules of inference: this is what the traditional philosophy of science has focussed on, debating the nature of these rules, i.e. whether they are lawful, and if so, what their lawfulness consists in, whether they function as mere inference tickets from data to data or whether one should interpret them realistically, whether the different ontological structures require different kinds of law-like generalizations, etc. Finally, the rules of scope also change over time: new instructions about where and how to apply the 
explanatory rules to new phenomena are issued, debated and followed by the participating scientists.

The explanations offered by the participants of an explanatory game evolve over time as they follow the different kinds of rules available to them. Explanatory knowledge is just a part of general human knowledge that is a product of genetic and cultural evolution. The process of cultural evolution concerns the change and transmission of knowledge in time at a societal level, and it can be regarded as a process of collective learning (Mantzavinos, 2001, p.73). Donald (1991), in his Origins of the Modern Mind, highlights the function of what he calls "External Symbolic Storage" for the transmission and accumulation of knowledge across generations. It was the simple habit of recording ideas, that is, "of externalizing the process of oral commentary of events" (p. 342) that constituted the critical innovation that has massively supported the evolution of theoretic culture. This occurred in Greece beginning around $700 \mathrm{BCE}$. What was truly innovative was that "for the first time in history complex ideas were placed in the public arena, in an external medium, where they could undergo refinement over the longer term, that is, well beyond the life-span of single individuals" (p. 344). These External Symbolic Storage Networks have decisively changed the character of knowledge evolution, since they provide the possibility of a constant interaction between the accumulated corpus of theoretical knowledge and the theoretical problems of the individuals in a society.

If one adopts an evolutionary perspective, then the thesis of a continuum between everyday, commonsensical knowledge and scientific knowledge, both products of the more general cultural evolutionary process, seems very plausible. The thesis of a continuum does not deny the difference in the quality of the scientific knowledge vis à vis other kinds of knowledge. But instead of focussing on clear-cut demarcation criteria of a syntactic nature (something that was fashionable for a long time in philosophy of science), it suggests that it is the specific way that knowledge is imposed for criticism that one should rather study. An institutional arrangement that enables criticism is the first prerequisite, of course. With this I mean that the institutional structure, both in its formal and in its informal elements, must allow or even encourage the criticism of knowledge structures and practices. A polity that guarantees 
the freedom of expression and allows for resources to be devoted to the building of organisational structures like universities, where everything is allowed to be questioned, provides the formal institutional structure that makes advanced criticism possible. A widespread critical attitude towards given beliefs and practices provides the informal institutional structure that enable criticism. The latter is more important (and has in fact come first historically). ${ }^{3}$ The specific mix of formal and informal institutions prevailing in a society regulates the behaviour of the individuals and provides the solution to what is (very inaccurately called) the problem of "power". ${ }^{4}$

In theocratic systems religious there is strong resistance to the criticism of religious explanations. Communist political systems have similarly regularly disallowed the development of explanatory games for the analysis of social phenomena other than the ones that the communist party has found acceptable. The range and amount of criticism thus decisively depends on the prevailing institutional framework - the freedom of thought and expression that enables scientific explanatory activities in modern universities and is guaranteed by liberal states around the world is only a contingent historical case.

\section{EPILOGUE}

Thus, explanatory games unfold through time in the context of specific institutional constraints, and in the broader context of an ongoing evolution of all human knowledge. The rules of representation, the rules of inference and the rules of scope followed by the participants of any specific game change over time. Since the ingredients of explanations come from the use of these different kinds of rules, their change over time is concomitant with a vertical division of explanatory labor. The broad picture of the division of explanatory labor consists, thus, both of a horizontal dimension comprising all explanatory games at a moment of time and of a vertical dimension encapsulating all changes of explanatory activities taking place within the diverse games over time. Working out exactly how these rules change over time can not be taken up here. That clearly remains clearly a desideratum. 


\section{NOTES}

1. This the translation in the Pinguin's Classics edition (1976). For a useful discussion of cosmogonic myths see Burkert (1999).

2. Thomas Kuhn (1962/1970, p. 106ff.) has drawn attention to that and van Fraassen (1980, p.111f) has raised the issue again in the theory of explanation: "Examples [Kuhn] gives of explanation requests which were considered legitimate in some periods and rejected in others cover a wide range of topics. They include the qualities of compounds in chemical theory (explained before Lavoisier's reform, and not considered something to be explained in the nineteenth century, but now again the subject of chemical explanation). Clerk Maxwell accepted as legitimate the request to explain electromagnetic phenomena within mechanics. As his theory became more successful and more widely accepted, scientists ceased to see the lack of this as a shortcoming. The same had happened with Newton's theory of gravitation which did not (in the opinion of Newton or his contemporaries) contain an explanation of gravitational phenomena, but only a description. In both cases there came a stage at which such problems were classed as intrinsically illegitimate, and regarded exactly as the request for an explanation of why a body retains its velocity in the absence of impressed forces. While all of this may be interpreted in various ways (such as through Kuhn's theory of paradigms) the important fact for the theory of explanation is that not everything in a theory's domain is a legitimate topic for why-questions; and that what is, is not determinable a priori.)".

3. See Popper (1963/1989, p.50): "For the critical attitude is not so much opposed to the dogmatic attitude as super-imposed upon it: criticism must be directed against existing and influential beliefs in need of critical revision-in other words, dogmatic beliefs. A critical attitude needs for its raw material, as it were, theories of beliefs which are held more or less dogmatically. Thus science must begin with myths, and with the criticism of myths; neither with the collection of observations, nor with the invention of experiments, but with the critical discussion of myths, and of magical techniques and practices. The scientific tradition is distinguished from the pre-scientific tradition in having two layers. Like the latter, it passes on its theories; but it also passes on a critical attitude towards them. The theories are passed on, not as dogmas, but rather with the challenge to discuss them and improve upon them. This tradition is Hellenic: it may be traced back to Thales, founder of the first school (I do not mean 'of the first philosophical school', but simply 'of the first school') which was not mainly concerned with the preservation of a dogma."

4. I have developed my own theory of institutions which gives what I think a more accurate account of how "power"-indeed a very vague and thus, a useless oneis regulated in a society. See Mantzavinos (2001). 


\section{REFERENCES}

Bartelborth, Thomas (2002) "Explanatory unification", Synthèse, 130: 91-107. Bible, Old Testament.

Burkert, Walter (1999) “The Logic of Cosmogony”, in Richard Buxton (ed.), From Myth to Reason? Studies in the Development of Greek Thought. Oxford: Oxford University Press, pp. 87-106.

Charkaoui, Mohamed (2005) Invisible Codes. Essays in Generative Mechanisms. Oxford: The Bardwell Press.

Demeulenaere, Pierre (ed.) (2011) Analytical Sociology and Social Mechanisms. Cambridge: Cambridge University Press.

Donald, Merlin (1991) The Origins of the Modern Mind. Three Stages in the Evolution of Culture and Cognition. Cambridge/Mass.: Harvard University Press.

Friedman, Michael (1974) “Explanation and Scientific Understanding." Journal of Philosophy, 71: 5-19.

Hedström, Peter, and Richard Swedberg (eds) (1996) Social Mechanisms. An Analytical Approach to Social Theory. Cambridge: Cambridge University Press.

Hesiod (1976) Theogony. London: Penguin Classics.

Kitcher, Philip (1981) "Explanatory unification", Philosophy of Science, 48: 251-281.

_ (1989) "Explanatory unification and the causal structure of the world", in Philip Kitcher and Wesley Salmon (eds), Scientific Explanation, volume 13 of Minnesota Studies in the Philosophy of Science, pp. 410-505.

Kuhn, Thomas (1962/1970) The Structure of Scientific Revolutions, second enlarged edition. Chicago: Chicago University Press.

Machamer, Peter, Lindley Darden, and Carl Craver (2000) "Thinking about mechanisms", Philosophy of Science, 67: 1-25.

Mantzavinos, C. (2001) Individuals, Institutions and Markets. Cambridge: Cambridge University Press.

- (ed.) (2009) Philosophy of the Social Sciences. Philosophical Theory and Scientific Practice. Cambridge: Cambridge University Press.

- (2013a) "Explanation" in: International Encyclopedia of the Social and Behavioral Sciences, 2nd edition (forthcoming).

- (2013b) "Explanatory games" (unpublished manuscript).

Popper, Karl R. (1963/1989) Conjectures and Refutations. The Growth of Scientific Knowledge, 5 th revised edn. London: Routledge.

Salmon, Wesley (1984) Scientific Explanation and the Causal Structure of the World. Princeton, NJ: Princeton University Press.

van Fraassen, Bas C. (1980) The Scientific Image. Oxford: Clarendon Press.

Woodward, James (2003) Making Things Happen. Oxford: Oxford University Press. 
